\title{
UM ESTUDO SOBRE ESCOLAS COM PEDAGOGIAS DIFERENCIADAS: A PEDAGOGIA WALDORF, A PEDAGOGIA MONTESSORI E A ESCOLA DA PONTE EM FOCO
}

\author{
A STUDY ABOUT SCHOOLS WITH DIFFERENTIATED PEDAGOGIES: THE \\ PEDAGOGY WALDORF, THE PEDAGOGY MONTESSORI AND THE 'ESCOLA \\ DA PONTE' IN FOCUS
}

\author{
Fernanda Luiza Faria ${ }^{1}$ \\ Ivoni Freitas-Reis ${ }^{2}$
}

\begin{abstract}
Resumo
O presente estudo discorre sobre três pedagogias que apresentam projetos de ensino diferentes ao padrão escolar: Pedagogia Waldorf, Pedagogia Montessori e o projeto Fazer a Ponte. Alicerçados no referencial teórico da pedagogia diferenciada e concomitantemente, com uma educação que promova uma cultura científica básica a seus estudantes, este estudo de caráter teórico se faz sob o contexto do ensino de química estabelecido nestas instituições. Como base para essa abordagem tem-se uma pesquisa documental em sites de escolas que seguem as pedagogias investigadas, livros e artigos que discutem sobre as mesmas, bem como observação de três escolas - uma que segue a Pedagogia Waldorf, uma que segue a Pedagogia Montessori, ambas no Brasil, e ainda a observação na Escola da Ponte, localizada em Portugal. Este trabalho tornou-se significativo, na medida que trouxe discussões sobre temáticas ainda pouco familiares ao contexto das pesquisas educacionais e do próprio cotidiano dos professores em geral. Ademais abordou inspirações e discussões que possibilitaram uma reflexão acerca do ensino que se constitui atualmente nas escolas e como algumas mudanças de ideais, organizacionais e comportamentais podem modificar um espaço escolar.
\end{abstract}

Palavras-Chave: Pedagogia Diferenciada, Pedagogia Waldorf, Pedagogia Montessori, Escola da Ponte.

\begin{abstract}
The present study discusses three pedagogies that present teaching projects different from the school standard: Waldorf Pedagogy, Montessori Pedagogy and 'Escola da Ponte'. Based on the theoretical framework of differentiated pedagogy and concomitant with an education that promotes a basic scientific culture for its students, this theoretical study is done under the context of the teaching of chemistry established in these pedagogies. As a basis for this approach, did for a documentary search on sites of schools that follow such

\footnotetext{
${ }^{1}$ A autora é doutoranda em Química, linha de pesquisa em Educação em Química pela Universidade Federal de Juiz de Fora. E-mail: fernanda.ldefaria@gmail.com - PUCSP. Atualmente é professora permanente - adjunto IV desde março de 2017 - da Universidade Federal de Juiz de Fora - UFJF.

E-mail: ivoni.reis@ufjf.edu.br
}

2 A autora é Doutora em História da Ciência pela Pontifícia Universidade Católica de São Paulo
\end{abstract}


these pedagogies investigated, books and articles that discuss about the same, as well as observation of three schools - one that follows to Waldorf Pedagogy, one that follows Montessori Pedagogy, both in Brazil, and an observation in the 'Escola da Ponte, located in Portugal. This work has become significant in that it has brought discussions about as yet unknown topics on context of educational research and the everyday life of teachers in general. In addition, has addressed inspirations and discussions that allowed for reflection on current education in schools and how some changes in ideals, organizational and behavioral can modify the school space.

Key-words: Differentiated Pedagogy, Waldorf Pedagogy, Montessori Pedagogy, 'Escola da Ponte'.

\section{Introdução}

Uma escola que busca estabelecer uma pedagogia diferenciada, cuja trajetória vem romper com os programas anuais massivos e respeitar a individualidade do aluno em seu percurso, merece e demanda toda a atenção dos educadores do século XXI. Concordamos com Perrenoud (2000), quando afirma que "a diferenciação da pedagogia e a individualização das trajetórias de formação estão, ou estarão, no centro das políticas de educação dos países desenvolvidos" (p. 10). Ao longo dos anos, tem-se deparado com um aumento de diferentes projetos políticos pedagógicos em algumas escolas em torno do mundo, o que se estende inclusive ao Brasil, a fim de promover uma diferenciação pedagógica.

Neste âmbito, este estudo de caráter teórico vem contemplar discussões acerca da pedagogia diferenciada, retratando preceitos e ideais que sustentam essa temática, bem como, instituições estabelecidas no Brasil e fora dele que tem buscado um compromisso educacional que converge com a pedagogia diferenciada. Ainda neste contexto, visa-se expandir um pouco mais esse debate em torno do Ensino de Ciências e a preocupação de se estabelecer uma cultura científica básica, discutindo como estas instituições que propagam um ensino diferenciado vêm atender a esse objetivo.

Analisando o fracasso escolar, estudiosos como Perrenoud (2000), Morgan (2014), Santos (2009) buscam a diferença no interior da prática pedagógica, na realização de um ensino significativo para todos. Numa sociedade escolarizada sempre encontraremos espaços educacionais que 
ignoram os seus fracassos e outros que valorizam e buscam diferenças. Nos dizeres de Perrenoud (2000):

As pedagogias diferenciadas incluem-se no objetivo da escola, que continua sendo o de oferecer a todos uma cultura básica comum. Sem renunciar à diversificação, seu desafio vai além: conseguir que todos os alunos tenham acesso a essa cultura e dela se apropriem. Considerar as diferenças é, então, colocar cada aluno diante de situações ótimas de aprendizagem. As pedagogias diferenciadas aceitam esse desafio e propõem inovações nas maneiras de resolver o problema. (PERRENOUD, 2000, p.1).

O trabalho de Perrenoud (2000) aponta que a visão de pedagogia diferenciada não é uma ideia nova, ela teve origem em pensamentos antigos, estabelecidos no período da Escola $\mathrm{Nova}^{3}$. A pedagogia diferenciada se estabelece, conforme mencionamos, como um caminho para romper com a visão de ensino que considera que todos os alunos aprendem de forma igual e, portanto, estabelecem um mesmo formato de ensino para todos. Assim, ela se estrutura na compreensão de que todos possuem o direito de aprendizagem, sendo o aprender, uma ação complexa que requer ponderar as necessidades individuais do aluno. (CAVALHEIRO; TEIVE, 2013; SANTOS, 2009).

Neste caminho, como destaca Santos (2009), as diferenças de aprendizagem dos alunos vão além do tempo que este sujeito necessita para compreender um conhecimento, abarcando principalmente as diversas maneiras de pensar e relacionar os conhecimentos prévios com os conhecimentos novos construídos. É preciso evidenciar e ensinar a partir das diferentes potencialidades e estilos de aprendizagem de cada aluno (MORGAN, 2014). Trata-se de uma abordagem singular, com a preocupação de trabalhar a educação de forma mais centrada no aluno e em seu percurso. Um processo

\footnotetext{
3 A Escola Nova surgiu no final do século XIX e teve grande força no início do século XX, trazendo propostas que envolviam ideais contrários ao ensino tradicional vigente na época. $\mathrm{O}$ movimento escolanovista atingiu diferentes países e envolveu vários estudiosos, e assim, não fazia menção a um único modelo de escola. Dentre as bandeiras defendidas por este movimento e que permanecem atuais no ambiente escolar temos: currículo por projetos, preocupação com o interesse da criança, mobiliário adaptado para cada faixa etária, discursos sobre a liberdade do educando, dentre outros (CAVALHEIRO; TEIVE, 2013).
} 
que visa “[...] privilegiar uma regulação interativa, colocar os alunos em situações de aprendizagem e diferenciar nesse âmbito, sem estabilizar grupos de níveis". (PERRENOUD, 2000, p.42).

Promover uma pedagogia diferenciada é um desafio que envolve a reflexão e mudança dos nossos conhecimentos, das nossas divergências, podendo os resultados dessas mudanças demorarem para serem vistos (PERRENOUD, 2000). Grimes e Stevens (2009) atentam para alguns aspectos que caracterizam um ensino diferenciado como a responsabilidade e a escolha do aluno, o agrupamento flexivel, a interação entre grupos. Seguindo esta vertente, os autores Tomlinson e Allan (2002) estabelecem outros pontos que representa um espaço que busca promover um ensino diferenciado:

Uma sala de aula onde se diferenciam as situações de ensino e aprendizagem caracteriza-se pela flexibilização do processo de intervenção pedagógica que aí ocorre (o tempo, materiais, metodologias de ensino, etc.); a diferenciação do processo de intervenção pedagógica decorre da avaliação eficaz e contínua das necessidades dos alunos; uma organização flexível dos tipos de agrupamentos dos alunos necessários para realizar as suas atividades académicas permite que estes acedam a uma ampla variedade de oportunidades de aprendizagem e propostas de trabalho; todos os alunos trabalham consistentemente com propostas de trabalho e atividades adequadas e desafiantes; os alunos e os professores são colaboradores no âmbito do processo de aprendizagem. (TOMLINSON; ALLAN, 2002, p. 18-21).

No viés da pedagogia diferenciada, cabe discutir ainda que o processo educativo se estabelece sobre o tripé: aluno, professor e saber. Diante disso, é importante ressaltar sobre o papel do professor na busca por uma abordagem de ensino diferenciada, que promova uma aprendizagem efetiva para todos os alunos. Para isso, torna-se necessário que esse profissional conheça as potencialidades, limitações e as demais características dos seus alunos, que aprecie e se interesse por promover espaços e estratégias de ensino desafiadores e diferenciadas. O professor deve ainda, centrar na identificação de ações educativas que promovam a igualdade de acesso dos alunos ao currículo, e de oportunidades de aprendizagem que respeitem seu ritmo de aprendizagem (HENRIQUES, 2016). Isto posto, a observação e reflexão tornam-se ações essenciais à pratica docente, devendo ocorrer 
constantemente durante sua atuação. De fato, o professor que busca promover um ensino diferenciado, tem um trabalho árduo e complexo, mas que traz mais significado e prazer ao seu exercício docente.

Frente às discussões acerca da pedagogia diferenciada, almeja-se neste momento, expandir um pouco mais esse debate, se adentrando para o contexto do Ensino de Ciências, um dos objetivos já descritos inicialmente para esse presente estudo teórico. Para isso, realizamos uma breve discussão acerca da promoção de um Ensino de Ciências que promova uma cultura científica básica aos estudantes.

\section{O Ensino de Ciências e a perspectiva de promover uma cultura científica básica a todos}

Como destacou Perrenoud (2000), em um trecho anterior a este tópico, as pedagogias diferenciadas integram-se no propósito de que uma instituição escolar deve propiciar a todos uma cultura básica comum, o que contempla a cultura científica. Todavia, o currículo de ciências tem como histórico o caráter de preparação de futuros cientistas, logo, é comum nos depararmos, nas escolas, em geral, com currículos dessa área encharcados de conteúdos de química, biologia e física, comumente trabalhados de forma isolada e desconsiderando a abordagem de outras ciências.

Em decorrência disso, os conhecimentos científicos não têm sido compreendidos pelos alunos, que normalmente demonstram-se incapazes de empregar o saber científico em situações problemáticas simples, tendo uma bagagem muito pobre de conhecimentos básicos referentes à ciência (MILLAR, 2003). Ademais, a abordagem científica, da maneira como acontece nos espaços escolares, contribui para uma visão deformada da ciência, estabelecendo uma imagem de algo alheio e inatingivel, que não desperta o interesse de quem a estuda (CACHAPUZ et al., 2005). Esse conhecimento deveria contribuir para o desenvolvimento de competências e habilidades importantes para a formação pessoal do aluno, bem como, fornecer subsídios para compreender melhor o mundo natural e os fenômenos científicos que o integram, a tomar decisões práticas sobre questões do cotidiano, envolvendo 
também aspectos mais específicos sobre ciência e tecnologia (MILLAR, 2003). Acreditamos e defendemos que o Ensino de Ciências deveria ter como prioridade o acesso à cultura científica básica (MILLAR, 2003).

Neste processo, foram também propostos ao longo dos anos no Brasil, documentos oficiais que trouxeram discussões sobre a abordagem do Ensino de Ciências para o alcance do objetivo maior da educação básica: a formação de cidadãos críticos e ativos em sociedade, como, por exemplo, os Parâmetros Curriculares Nacionais - PCN (Brasil, 1998). Todavia, a realidade aponta para uma carga desanimadora e pesada de conteúdos desconexos nas escolas de pedagogias tradicionais, havendo ainda uma grande lacuna entre a teoria e a prática que se estabelece nas escolas.

Alicerçados nas ponderações anteriores, definimos, como pano de fundo teórico, as discussões acerca da pedagogia diferenciada e a busca por um ensino que promova uma aprendizagem significativa e uma formação mais ativa e crítica para todos e ainda discussões sobre o anseio por um Ensino de Ciências que promova uma cultura científica básica a todos. Esta última discussão, de certa forma, demonstrou ser uma abordagem que vai ao encontro de muitos anseios da pedagogia diferenciada.

Isto posto, visamos neste momento discorrer sobre três pedagogias que pregam uma proposta pedagógica diferenciada - a Pedagogia Waldorf, a Pedagogia Montessori e o projeto Fazer a Ponte - atentando para os aspectos que as fundamentam e que convergem com os preceitos teóricos da pedagogia diferenciada e, concomitantemente, com uma educação que promova uma cultura científica básica a seus estudantes. Essa discussão se faz sob o contexto do ensino de química estabelecido nestas instituições.

Assim, neste momento, julga-se necessário detalhar um pouco sobre cada pedagogia citada, a fim de clarear sobre seus objetivos educacionais e organização institucional. Como base para essa abordagem tem-se uma pesquisa documental em sites de escolas que seguem as pedagogias investigadas, livros e artigos que discutem sobre as mesmas, bem como observação de três escolas - uma que segue a Pedagogia Waldorf, uma que segue a Pedagogia Montessori, ambas no Brasil, e ainda a observação na 
Escola da Ponte, localizada em Portugal - provenientes de resultados construídos a partir de uma tese ainda em andamento, que investigou o ensino de química estabelecido nestas instituições no ensino fundamental.

\section{Uma breve discussão acerca da organização e dos preceitos pedagógicos que constituem a Pedagogia Waldorf, a Pedagogia Montessori e o Projeto Fazer a Ponte}

Há mais de 95 anos a primeira Escola Waldorf foi fundada e de lá para cá, o número de escolas no mundo só vem crescendo. Segundo Alves (2011), em 2010 havia aproximadamente 650 escolas na Europa, no mundo todo havia mil escolas espalhadas em 61 países e mais de 1600 Jardins de Infância. No Brasil, em 2016, segundo a Federação das Escolas Waldorf (FEWB), havia 33 escolas filiadas que possuem o Ensino Infantil, 20 com o Ensino Infantil e o Fundamental e 10 que apresentam além do Ensino Infantil e Fundamental, também o Ensino Médio. Dessas 10 escolas, 8 se encontram no estado de São Paulo, 1 no estado de Minas Gerais e 1 no estado de Santa Catarina. As Escolas Waldorf são reconhecidas pelo MEC e pela UNESCO e trazem uma perspectiva educacional bem diferenciada das escolas tradicionais.

A Pedagogia Waldorf foi constituída no final da primeira guerra mundial, na Alemanha. Especificamente em 1919, o diretor de uma fábrica de produção de cigarros designada Waldorf-Astoria, Emil Molt (1876-1936), ofereceu a Rudolf Steiner ${ }^{4}$ (1861-1925), a responsabilidade de construção de uma instituição escolar para a formação dos filhos dos operários e dos funcionários da fábrica. Esta escola seria baseada nos preceitos da Antroposofia, também difundida por Steiner no início do século XX.

Para Steiner essa pedagogia tinha como objetivo principal formar seres humanos livres que pudessem ser capazes de, por si mesmos, encontrar propósito e direção para suas vidas. A Pedagogia Waldorf visa a formação do

\footnotetext{
${ }^{4}$ Rudolf Steiner foi um filósofo, cientista e artista. Ele nasceu em 27 de fevereiro de 1861, em Donji Kraljevec, em uma região chamada Medjimurje, Croácia, entre a Hungria e a Eslovênia. Steiner viveu toda sua infância e parte da sua juventude na Áustria. Ele formou-se na Escola Politécnica de Viena em engenharia e concluiu em 1890 o seu doutorado em Filosofia na Universidade Rostock, na Alemanha. Em 1910 se dedicou a criar a Antroposofia. Ele Faleceu em 1925 na Suiça.
} 
ser humano como um todo, desenvolvendo diferentes aspectos de forma harmoniosa como a inteligência, a vontade, ideais sociais, conhecimentos, moral, entre outros (BOGARIM, 2012). Os três princípios que regem uma Escola Waldorf são: a liberdade quanto às metas de educação; a liberdade quanto ao método pedagógico; e a liberdade quanto ao currículo; de forma que a escola seja, portanto, autônoma. O indivíduo deve estar preparado para conhecer o mundo que o cerca e atuar e viver dentro dele (LANZ, 2003).

No contexto da sala de aula, os alunos que a compõe apresentam a mesma faixa etária, entretanto, buscam estabelecer uma diversidade na turma, por exemplo, com estudantes com etnias diferentes, com aptidões intelectuais e artísticas e ainda com dificuldades psicomotoras ou de aprendizagem. O ensino das disciplinas de conteúdos mais específicos como química, fisica, história, geografia, dentre outros, ocorrem nas Escolas Waldorf em períodos, o que são chamados de épocas. Com exceção da disciplina matemática e português, que ocorrem mais vezes ao longo do ano, as demais são lecionadas ao longo de três ou quatro semanas seguidas no ano ao invés de as diluir em duas ou três aulas por semana, durante o ano todo.

As escolas Montessori, por sua vez, estão espalhadas nos cinco continentes, estando normalmente filiadas às associações que estabelecem contato entre si. No Brasil, segundo o site da Organização Montessori do Brasil $(\mathrm{OMB})^{5}$, estão registradas 40 escolas: 2 na região Norte, 11 no Nordeste, 15 no Sudeste, 3 no Centro-oeste e 9 na região Sul. Atualmente, o movimento Montessori tem se difundido cada vez mais ao longo de todo o Brasil e se tornado mais sólido, sendo conhecido e admirado pelo grande público em geral, bem como pelas mídias sociais.

Esta pedagogia foi criada por Maria Montessori6 (1870-1952) em 1907, quando começou a dar aulas para crianças em uma moradia instituída em

\footnotetext{
${ }^{5}$ A Organização Montessori do Brasil (OMB) teve origem em 20 de setembro de 1996, durante o IX Encontro Nacional de Diretores de Escolas Montessorianas, que ocorreu na cidade de Recife, Pernambuco. A OMB surge do anseio de encontros e compartilhamento de experiências entre escolas brasileiras que adotavam o Sistema Montessori. Para saber mais pode-se acessar o site da OMB: http://omb.org.br/

${ }^{6}$ Maria Montessori nasceu em 1870 em Chiaravalle, localizada próxima a Ancone na Itália. Filha única de um casal de classe média, seu interesse pelas Ciências era manifestado desde
} 
um bairro pobre no centro da cidade de Roma. Neste local, ela fundou a Casa dei Bambini, uma escola em que seus preceitos foram realizados na prática, e na qual buscava propiciar às crianças a "[...] aprender a conhecer o mundo e a desenvolver sua aptidão para organizar a própria existência”. (RÖHRS, 2010, p.14).

Ferrari (2014) destaca que as bases da teoria Montessori estão na individualidade, na atividade e na liberdade do aluno. Sua teoria entende o indivíduo como sujeito e objeto do ensino simultaneamente e retrata que a educação para Montessori tem como finalidade uma formação integral, uma educação para a vida. Na Pedagogia Montessori a autoaprendizagem é estabelecida como algo inerente ao ser humano e por isso tem sua educação pautada na autoeducação e, para que isso aconteça, é necessário um ambiente que prevaleça a democracia e que o ato de aprender seja um prazer para o aluno. (LIMA, 2007).

$\mathrm{Na}$ organização das classes nas Escolas Montessori há uma subdivisão das faixas etárias, conhecido como agrupadas. Assim, na Educação Infantil geralmente há uma agrupada com crianças de 0 a 3 anos e outra com crianças de 3 a 6 anos. No Ensino Fundamental há uma agrupada com crianças de 6 a 9 anos, outra com crianças de 9 a 12 anos e uma outra com jovens de 12 a 15 anos. Nesta proposta Montessori, temos uma organização bem diferente da realidade escolar brasileira, pois rompe com a estruturação do ensino em salas com alunos de uma única idade, divididos em anos.

Por fim, ao que se refere à Escola da Ponte, tem-se um projeto que, ao longo dos anos, tem ganhado cada vez mais visibilidade nacional e internacional. Segundo reportagem do O Globo Educação (BENEVIDES; RIBEIRO, 2012), o projeto Fazer a Ponte tem inspirado em torno de cem escolas brasileiras, que pensam em realizar importantes mudanças em seus espaços educativos. A reportagem ainda destaca que segundo José Pacheco,

a infância. Ela estudou medicina na Universidade de Roma e sofreu muita resistência por parte do pai e outras pessoas a sua volta devido a essa escolha (FERRARI, 2014). Montessori graduou-se no curso de Pedagogia, Antropologia e Psicologia. 
vinte das cem escolas estão mais à frente nessas discussões. Essas instituições, públicas e particulares, encontram-se principalmente nos estados de Minas Gerais, Porto Alegre, Paraná e São Paulo.

A Escola da Ponte encontra-se em São Tomé de Negrelos, freguesia do concelho de Santo Tirso, distrito de Porto, em Portugal (Escola da Ponte, 2015). Ela foi fundada em 1932, sendo uma das sete escolas públicas que se encontram nesta região. José Francisco de Almeida Pacheco (1951-) foi o principal responsável pela reorganização da escola, com a criação de um projeto inovador para essa instituição que teve início em 1976 e o qual é refletido, discutido e reformulado pelos professores ao longo dos anos. (SANTOS, 2015).

O projeto Fazer a Ponte teve origem sob um contexto problemático "o isolamento face à comunidade de contexto, o isolamento dos professores, a exclusão escolar e social de muitos alunos, a indisciplina generalizada e agressões a professores, a ausência de um verdadeiro projeto e de uma reflexão crítica das práticas" (PACHECO, 2013, p.12). Após a reorganização pedagógica, a Escola da Ponte passou a se estruturar em valores como a solidariedade, a liberdade, a autonomia, a democraticidade, a responsabilidade e a cooperação. Como bem destaca a escola em seu site, a organização dessa instituição "inspira uma filosofia inclusiva e cooperativa que se traduz em aspectos muito simples: todos precisamos de aprender, todos podemos aprender uns com os outros e quem aprende, aprende a seu modo no exercício da Cidadania" (Escola da Ponte, 2015). Um projeto reconhecido e assumido por alunos, pais, profissionais de educação e os demais agentes educativos.

A Escola da Ponte compreende os três ciclos básicos da Educação Básica, como assim é nomeado em Portugal, o que se refere aos anos do Ensino Fundamental no Brasil. Nesta instituição não há séries, anos, mas sim três núcleos, o de Iniciação, o de Consolidação e por fim o de Aprofundamento, seguindo esta ordem de desenvolvimento. 


\section{Discussões sobre o ensino de química estabelecido nas escolas Waldorf, Montessori e Ponte e os preceitos de uma pedagogia diferenciada}

As pedagogias destacadas anteriormente apresentam filosofias de ensino próprias e organizações e estruturas educacionais fora dos padrões escolares. Há muitos aspectos que tangenciam a proposta de um ensino para todos, caracterizando instituições que praticam uma pedagogia diferenciada. Frente a isso, cabe discutir e refletir um pouco acerca desses aspectos.

Já de imediato, as três pedagogias: Waldorf, Montessori e Escola da Ponte, se assemelham à proposta de diferenciação pedagógica na busca por um ensino mais justo para todos, que considera as particularidades de cada aluno, bem como numa formação humana, que prepara o aluno para a participação ativa e crítica na sociedade (PERRENOUD, 2000; SANTOS, 2009). Objetivo que inclusive converge com os preceitos que estruturam os documentos oficiais que regem a educação brasileira como a própria Lei de Diretrizes e Bases da Educação Nacional - LDB (BRASIL, 1996).

Neste contexto, cabe ressaltar ainda para a grande responsabilidade e comprometimento do aluno da Escola da Ponte com a instituição e seu aprendizado. O que vai desde a apresentação da instituição aos visitantes ao que se estende a reuniões de debate e assembleias de escola, até sua própria postura durante o momento de aprendizagem. Este momento que se sustenta em uma construção progressiva de sua própria autonomia, uma vez que se torna responsável em gerir seu tempo e espaço, planejar suas atividades e avaliações. (CANÁRIO et al., 2004).

Particularmente, é preciso detalhar mais sobre uma especificidade da Escola da Ponte que demonstra grande potencial para a formação crítica do aluno, a assembleia realizada semanalmente pelos alunos na instituição. Esse evento, organizado e coordenado pelos próprios alunos, contribui para instigar o desenvolvimento de competências e habilidades importantes para a formação do aluno, como por exemplo, a argumentação, a comunicação, a tomada de decisão, dentre outras.

Neste caminho, seguindo os princípios que Tomlinson e Allan (2002) apontam como características de um espaço que promove um ensino 
diferenciado, a proposta de uma sala de aula que diferencia as situações de ensino e aprendizagem pode ser evidenciada nas três instituições em discussão, devido à flexibilização do processo de intervenção pedagógica que é estabelecido nestes espaços e da ênfase na centralização do aluno e de seu percurso. (PERRENOUD, 2000).

Ao que se refere em reestruturação da sala de aula, por exemplo, a Escola Montessori e a Escola da Ponte se comprometem em estabelecer um ensino diferenciado na medida que rompem com o formato tradicional de cadeiras enfileiradas e o professor como transmissor de conteúdo, dando a esse sujeito, mais liberdade e autonomia na sua aprendizagem, a partir de estudos independentes. E ainda quando instiga a troca de opiniões e experiências entre os alunos quando os organiza em grupos, características discutidas por Morgan (2014) como significativas a um ensino diferenciado.

Estas escolas vêm ao encontro da proposta de um ensino mais justo quando organiza em espaços onde alunos de diferentes idades convivem juntos, os organizando em agrupamentos, na Escola Montessori, e em níveis, na Escola da Ponte, ambos com intervalo de três anos aproximadamente. A ruptura com o formato tradicional da escola é compreendida por Perrenoud (2000) como algo essencial para um espaço educacional que busca um ensino para todos. Este autor destaca que a criação de ciclos de aprendizagem, de pelo menos dois a três anos, no qual dentro destes não ocorre reprovação, nem qualquer outra forma de seleção, é uma condição necessária de progresso. Sobre o mesmo refere-se a importância deles terem os alunos sob a confiabilidade de uma pessoa ou de uma pequena equipe, durante todo o ciclo. Após cada ciclo poderia se ter uma avaliação mais profunda. Aspectos que são trabalhados na Escola da Ponte e na Pedagogia Montessori de forma satisfatória.

A postura adotada pelo professor nestas instituições também vai ao encontro dos anseios da pedagogia diferenciada pregado por Perrenoud (2000), Henriques (2016) e Tomlinson e Allan (2002). Uma vez que este profissional estabelece um papel de colaborador e mediador do processo de ensino e aprendizagem e ainda busca comunicar, construir vinculo humano e 
forte com o aluno, de forma que ele se sinta bem naquele espaço de aprendizagem e com prazer de aprender. Ademais, na proposta de pedagogia diferenciada, a autonomia do professor se torna muito importante, deve haver uma liberdade maior para esse profissional exercer seu oficio, individual e coletivamente. Como problematiza Perrenoud (2000), não em um diálogo de cúpula entre as associações profissionais e ministérios, mas sim a partir de diálogos e trocas entre professores, diretores, pais e demais organizadores dos espaços escolares, o que se faz presente nas três pedagogias estudadas.

$\mathrm{Na}$ Escola Waldorf, por exemplo, o professor é uma das figuras de respeito e apoio para o aluno. Ele tem um convivio diário com os seus alunos, o que fortalece a relação entre eles e permite que o docente consiga compreender melhor as qualidades e as limitações dos seus estudantes. Esse profissional normalmente acompanha o aluno do primeiro até o oitavo ano. Ele aborda as matérias tradicionais, na qual Lanz (2003) declara que o professor não necessita de uma formação específica, como: linguagem, aritmética, geografia, história, física, química e caso sinta à vontade e afim, pode ainda se tornar responsável por disciplinas como os trabalhos manuais e a educação física. Quando os alunos chegam ao nono ano, esse formato é modificado e as disciplinas passam a ser ministradas por professores especializados nas diferentes áreas. Há ainda um professor tutor para cada classe que atua como um elo entre os alunos e a escola e inclusive, com os pais. Esse tutor na maioria das vezes é escolhido pelos próprios alunos.

Ao que se refere ao trabalho do professor na Escola Montessori não é menor ou mais fácil, pelo fato de a criança ter tanta autonomia. É necessária uma preparação muito grande para que ele consiga atender à grande demanda de interesse mental da criança. O professor tem que ser alegre, observador e estimular a aprendizagem do aluno. (MONTESSORI, 2003).

$\mathrm{Na}$ Escola da Ponte, o professor também é uma peça-chave, sendo um profissional com importância reconhecida e papel bem distinto dos modelos tradicionais de outras escolas. Para Canário (2004), a equipe de professores dessa escola tem como característica a persistência em sua autonomia, criatividade e dominio de sua profissão, de forma que para exercê-la, não seja 
necessária qualquer permissão. O professor nesta instituição, também chamado de orientador educativo, é um promotor de educação, e deve participar na concretização do projeto educativo da escola, mediar o percurso educativo de cada aluno e ainda apoiar os seus processos de aprendizagem (Escola da Ponte, 2015). O orientador educativo tem ainda outra função na Escola da Ponte, a de supervisionar permanentemente o trabalho de alguns alunos indiciados a ele, o que é apontado como uma função de tutor neste projeto da escola. Assim, o tutor torna-se responsável pela mediação entre o professor e a escola.

Acerca dos principios gerais que estruturam a pedagogia diferenciada, cabe detalhar sobre a avaliação. Para Perrenoud (2000), o processo de diferenciação em um ambiente escolar requer uma avaliação formativa, uma avaliação que permita que o aluno aprenda. Este tipo de avaliação pode ser evidenciado nas escolas Waldorf, Montessori e Escola da Ponte, que caracterizam por adotarem um processo avaliativo qualitativo, que considera a formação de valores, o desenvolvimento de competências e habilidades, o comprometimento e respeito com a escola, a relação entre aluno-aluno, aluno e professor, o itinerário de formação, a relação do aluno com o saber, dentre outros aspectos já citados no tópico referente a cada escola. Não há nestas instituições, a aplicação de provas tradicionais e nem são atribuídas notas aos rendimentos dos alunos.

Dentro deste contexto, cabe ainda destacar sobre o processo de auto avaliação, adotado pela Escola da Ponte, que é uma proposta de grande potencial para a promoção de um ensino que avalia satisfatoriamente a aprendizagem do aluno, as limitações, o desenvolvimento de valores, competências e habilidades, dentre outras questões.

No que concerne o Ensino de Ciências, há aspectos das três instituições estudadas que convergem com as discussões teóricas que permeiam a pedagogia diferenciada (PERRENOUD, 2000; TOMLINSON; ALLAN, 2002; Morgan, 2014; GRIMES; STEVENS, 2009) e ainda os referenciais teóricos, trazidos neste estudo, que ponderam sobre uma formação cidadã e o estímulo 
ao desenvolvimento de uma cultura cientifica básica. (BRASIL, 1998; MILLAR, 2003; CACHAPUZ et al., 2005).

Todas as três instituições em foco, enfatizam sobre a importância do conteúdo científico ser abordado no Ensino Fundamental a partir de uma visão mais integradora, permitindo a relação dos saberes das diferentes disciplinas que compõe as ciências da natureza, bem como de outros saberes, possibilitando uma compreensão mais significativa do todo. O que é uma característica discutida como essencial nos Parâmetros Curriculares Nacionais e a atual Base Nacional Comum Curricular (BRASIL, 1998; BRASIL, 2016) e ainda por Millar (2003) e Cachapuz et al. (2005).

Cabe destacar ainda dentro deste contexto, sobre o currículo Waldorf para o Ensino de Ciências, que se assemelha um pouco às propostas do PCN (BRASIL, 1998) para o Ensino de Ciências no Ensino Fundamental, quando se estrutura em eixos temáticos. Eixos esses que se inter-relacionam, aproximam da vivência do estudante e têm relevância para a formação desses sujeitos (BRASIL, 1998). Os conteúdos presentes no currículo desta escola provem de uma união entre as propostas de Steiner e as experiências obtidas ao longo dos anos nas Escolas Waldorf e ainda, das exigências curriculares de cada país. Especificamente sobre o currículo de ciências para o Ensino Fundamental, Sena (2013) destaca que:

Principalmente do $6^{\circ}$ ao $12^{\circ}$ ano, abarca temas que tendem a seguir um caminho que vai do concreto para o abstrato, que exercita do simples raciocínio lógico-causal a reflexões ampliadas, e busca cada vez mais estabelecer relações com a vida humana, norteando/objetivando um ganho crescente de autonomia por parte do educando. (SENA, 2013, p. 114).

No currículo de química, por exemplo tem-se, para o sétimo, oitavo e nono ano:

No EWC o estudo da Química se inicia no $7^{\circ}$ ano de maneira sistêmica, envolvendo processos químicos que envolvem o fogo, o ar, a água e a terra ('os 4 elementos' da antiguidade grega e da alquimia), como a combustão, respiração, fotossintese, formação de cavernas, oxidação, entre outros (7Q). Ao 'fogo' é dada especial atenção, por representar o processo pelo qual passam os alunos depois dos 12 
anos de idade. [...]. No $8^{\circ}$ ano é estudada a química orgânica, com ênfase nas substâncias estruturais ou que armazenam energia e servem para a alimentação (proteínas, carboidratos, lipídeos), além de processos dos quais essas substâncias participam, como a fermentação - do pão e do leite - e a saponificação (8Q). [...] Na química do $9^{\circ}$ ano ainda se estuda a química orgânica, a fermentação alcoólica e a destilação, além de processos que envolvem gases atmosféricos, como a combustão, a oxidação, a respiração e a fotossintese (9Q); também pode se tratar sobre os metais, as ligas metálicas e os aspectos históricos dos povos antigos com os metais, como a alquimia. (SENA, 2013, p. 111-112).

Quando se discute acerca da abordagem de temas amplos, Maldaner e Zanon (2004) destacam que essa é uma proposta utilizada já há algum tempo, de inúmeras formas por educadores, na busca de superar a disciplinaridade e fragmentação do ensino e conseguir relacionar os saberes com o cotidiano e realidade dos estudantes. No entanto, destacam que essa organização do ensino não consegue, em sua maioria, alcançar seus objetivos, declarando que não é uma tarefa simples de ser realizada em sala de aula pelos professores. Isso porque a realidade do ensino brasileiro ainda aponta para uma dependência dos professores diante do currículo tradicional, característico pela sua linearidade e fragmentação. Esse fracasso atinge inclusive aos PCN, que apesar de já estarem estabelecidos há alguns anos, não estão presentes na maioria das salas de aulas (MALDANER; ZANON, 2004). Assim, é significativo destacar a perspectiva da Pedagogia Waldorf em currículos temáticos, mostrando que ele pode ser adotado e trazer, efetivamente, muitas contribuições para o Ensino de Ciências e de outras áreas do conhecimento.

Outro aspecto evidenciado nas três escolas estudadas e que converge com os referenciais que retratam sobre pedagogia diferenciada (PERRENOUD, 2000; MORGAN, 2014; GRIMES; STEVENS, 2009; SANTOS, 2009) e as discussões teóricas sobre Ensino de Ciências trazidas aqui (MILLAR, 2003; CACHAPUZ et al., 2005) é a contextualização dos saberes. Como destaca Perrenoud (2000), o fato dos alunos não verem sentido no que lhe são colocados para aprender, propicia dificuldades no seu processo de aprendizagem. O que para o autor, está vinculado a uma concepção limitada das relações entre os saberes escolares e a prática social. "A escolaridade só 
tem sentido se o essencial do que nela se aprende possa ser investido fora dela, paralelamente ou mais tarde” (PERRENOUD, 2000, p.58). Ou seja, em situações da vida cotidiana, profissional, politica, familiar, pessoal, dentre outros contextos fora da escola. Na escola Waldorf especificamente, a ênfase em um currículo temático contribui muito para essa relação entre o conteúdo e a vivencia do aluno.

Dando continuidade a essa discussão, Morgan (2014) salienta que os alunos aprendem de forma diferente, ou seja, alguns podem ter uma aprendizagem mais significativa quando mobilizado o aspecto visual ou o verbal, a lógica, a espacial, dentre outros. Dessa forma, quando se possibilita estratégias que mobilizam diferentes habilidades, facilita o aprendizado do aluno e assim, criam-se maiores oportunidades para que esses sujeitos se tornem mais bem-sucedidos. Isso porque ao se utilizar de diferentes estratégias permite-se que o professor conheça mais sobre as potencialidades e limitações dos seus alunos.

Assim, acerca do uso de propostas de ensino diferenciadas, o comprometimento com a experimentação nas aulas estabelecidas na escola Waldorf merece discussão. Essa estratégia realizada nas aulas possui alguns aspectos marcantes e que são sempre enfatizados, como a observação do fenômeno, a percepção a partir dos sentidos e a vivência. Sobre uma situação de aprendizagem satisfatória, Perrenoud (2000) defende que deve ser uma situação desafiadora ao aluno, de forma que esse sujeito aceite o desafio e tenha meios para realiza-lo. Neste caminho, a prática experimental adotada na Waldorf atende aos aspectos enfatizados por Perrenoud (2000), bem como traz aspectos significativos enfatizados em referenciais teóricos acerca do Ensino de Ciências, como os próprios PCN. (BRASIL, 1998).

Outro ponto significativo da Escola Waldorf que se insere neste contexto de propostas variadas de ensino, é a grande ênfase dada à arte no currículo dessa pedagogia, sendo considerada uma "mediadora do processo de ensinoaprendizagem", de forma que além das disciplinas artísticas, a prática de ensino adotada para o estudo de qualquer conhecimento, envolve a habilidade artística do professor e do aluno. (SENA, 2013). 
Nas escolas Waldorf, o aluno 'constrói' sua própria fonte de estudo. Eles produzem cadernos, nos quais apontam as observações sobre a aula que julgaram mais relevantes. Esses saberes e observações são retratados no caderno através da escrita e da arte. Assim, todas as experiências realizadas no ensino das disciplinas de ciências da natureza são representadas a partir de desenhos feitos pelos próprios alunos.

Neste âmbito cabe discutir ainda sobre a ênfase da Pedagogia Montessori, na valorização do uso das mãos e do toque no processo de aprendizagem do aluno, que reflete no estímulo de atividades que enaltece as propriedades de um objeto, por exemplo, seu tamanho, textura, forma, cor, peso, cheiro, barulho, dentre outras. O que ocorre a partir dos materiais didáticos montessorianos, fortes nesta pedagogia. Trata-se de objetos simples, atraentes e construídos com a finalidade de provocar o raciocínio do aluno, sendo pensados para contribuir em diferentes aprendizados, "do decimal à estrutura da linguagem". (FERRARI, 2014, p.32).

Os materiais montessorianos são muito utilizados no Ensino Infantil e nos anos iniciais e intermediários do Ensino Fundamental com as crianças no espaço educativo. Esses materiais são focados em trabalhar a sensibilidade dos sentidos, são eles: básico, táctil, visual, auditivo, do cheiro, térmico, dentre outros (TAVARES, 2006). Para os últimos anos do ensino fundamental, não se tem materiais montessorianos pensados para a aprendizagem, e as escolas recorrem mais a livros didáticos.

\section{Considerações Finais}

A partir das discussões concretizadas neste estudo, não se pode deixar de refletir como os diferentes preceitos que contemplam os aportes teóricos da pedagogia diferenciada se encontram distantes da realidade escolar no Brasil. Todavia, é uma discussão que tem ganhado espaço no Brasil e no mundo, numa perspectiva mais prática, a partir da expansão de escolas que corroboram com um ensino diferenciado, que posiciona um olhar maior sobre o aluno e que, de fato, coloca em prática o que se prega em teoria. 
Este trabalho tornou-se significativo, na medida que trouxe discussões sobre temáticas ainda pouco familiares ao contexto das pesquisas educacionais e do próprio cotidiano dos professores em geral, como a discussão teórica que envolve a pedagogia diferenciada e principalmente exemplos de escolas que corroboram com essa filosofia de ensino. Muitas pessoas já ouviram falar da Pedagogia Montessori, da Waldorf e da Escola da Ponte, mas como instituições que distanciam muito dos padrões educacionais, sendo seus ideais não aplicáveis nas escolas. Todavia, as discussões que permearam este estudo apontaram aspectos que se tornam acessiveis e praticáveis nas escolas.

É reconhecido que ao se falar sobre a educação básica, estamos nos adentrando sobre uma realidade que envolve diferentes sujeitos e aspectos não só educacionais, como também politicos, econômicos, sociais e culturais. Todavia, este estudo não teve como intuito ditar como a educação básica deve se estabelecer, mas sim trazer inspirações e discussões que possibilitassem uma reflexão acerca do ensino que se constitui atualmente nas escolas e como algumas mudanças de ideais, organizacionais e comportamentais podem modificar um espaço escolar. O que julgamos ter sido possivel. Por fim, reforçamos a ideia de que conhecer, discutir e refletir sobre diferentes pedagogias educacionais é uma ação importante e significativa para as pesquisas educacionais, sendo uma vertente que deve ganhar mais espaço nesse contexto.

\section{Referências Bibliográficas}

ALVES, M. J. P. B. Uma experiência Física de um estudo emocional no ensino regular. Dissertação (Mestrado em ensino: artes visuais) - Universidade de Lisboa, Faculdade de Belas Artes de Lisboa, 2011.

BENEVIDES, C.; RIBEIRO, M. Todos juntos e misturados na escola. O Globo Educação. 2012. Disponivel em: <http:/ /oglobo.globo.com/sociedade/educacao/todos-juntos-misturadosna-escola-3677448>. Acesso em: set. 2015. 
BOGARIM, M. C. S. P. B. A qualidade da educação infantil no contexto da pedagogia Waldorf: um estudo de caso. Dissertação (Mestrado em Educação) - Faculdade de Educação, Universidade de Brasillia, 2012.

BRASIL. Lei de Diretrizes e Bases da Educação Nacional, Lei n ${ }^{\circ} .394,20$ de dezembro de 1996.

- Ministério da Educação e do Desporto. Secretaria da Educação Fundamental. Parâmetros curriculares nacionais: Ciências Naturais. Brasília: $\mathrm{MEC} / \mathrm{SEF}, 1998$.

- Ministério da Educação e do Desporto. Secretaria da Educação Fundamental. Base nacional comum curricular. Brasília, DF: MEC/SEF. $2^{\mathrm{a}}$ versão, 2016.

CACHAPUZ, A.; GIL-PEREZ, D.; PESSOA DE CARVALHO, A. M.; PRAIA, J.; VILCHES, A. (Org.). A necessária renovação do ensino das ciências. São Paulo, SP: Cortez Editora, 2005.

CANÁRIO, R.; MATOS, F.; TRINDADE, R. (Org.). Escola da Ponte: defender a escola pública. Portugal: Profedições, 2004.

CAVAlHEIRO, C. B.; TEIVE, G. M. G. Movimento Escolanovista: três olhares. XVI CONGRESSO NACIONAL DE EDUCAÇÃO - EDUCERE, Paraná, Curitiba. Anais... Curitiba: Pontifica Universidade Católica do Paraná, 2013, p. 21775-21787.

ESCOLA da ponte. Disponivel em: <http:// www.escoladaponte.pt $>$. Acesso em: jan. 2015 .

FERRARI, M. Maria Montessori: a médica que valorizou o aluno. Revista Nova Escola, 2014. Disponivel em:

<https://novaescola.org.br/conteudo/459/medica-valorizou-aluno>. Acesso em: jan. 2017.

GRIMES, K. J.; STEVENS, D. D. Glass, bug, mud. Phi Delta Kappan, v. 90, n. 9, p. 677-680, 2009.

HENRIQUES, R. F. S. Refletindo sobre a prática pedagógica em Educação de Infância e Ensino do $10^{\circ}$ Ciclo: estratégias de diferenciação pedagógica nos primeiros anos de vida. Dissertação - Mestrado em Educação Pré-Escolar e Ensino do $1 .^{\circ}$ Ciclo do Ensino Básico. Escola superior de educação e ciências sociais, Instituto Politécnico de Leiria, Portugal, 2016.

LANZ, R. A pedagogia Waldorf: caminho para um ensino mais humano. São Paulo, SP: Antroposófica, 2003. 
LIMA, E. Maria Montessori: conhecendo fundamentos, derrubando mitos. Revista Direcional Escolas, ano 3, edição 27, 2007.

MALDANER, O. A.; ZANON, L. B. Situação de estudo: uma organização do ensino que extrapola a formação disciplinar em ciências. In: MORAES, R.; MANCUSO, R. (Org.). Educação em ciências: produção de currículos e formação de professores. Ijuí, RS: Editora Unijuí, 2004, p. 43-64.

MILLAR, R. Um currículo de Ciências voltado para a compreensão por todos. Ensaio: Pesquisa em Educação em Ciências, v. 5, n. 2, p. 73-91, 2003. Disponivel em: <http://www.scielo.br/scielo.php?pid=S1983$21172003000200146 \&$ script=sci_abstract\&tlng=pt> Acesso em: jun. 2017.

MONTESSORI, M. Para educar o potencial humano. Tradução: Miriam Santini. São Paulo, SP: Editora Papirus, 2003.

MORGAN, H. Maximizing Student Success with Differentiated Learning. The Clearing House, v.87, p. 34-38, 2014.

PACHECO, J. Escola da Ponte: formação e transformação da educação. 5. ed., Petrópolis, RJ: Vozes, 2013.

PERRENOUD, P. Pedagogia Diferenciada: das intenções à ação. Tradução Patrícia Chittoni Ramos. Porto Alegre, RS: Artmed, 2000.

RÖHRS, H. Maria Montessori. Recife, PE: Fundação Joaquim Nabuco, Editora Massangana, 2010. (Coleção Educadores).

SANTOS, E. C. Formação de professores no contexto das propostas pedagógicas de Rudolf Steiner Pedagogia Waldorf, Maria Montessori e experiência da Escola da Ponte. 2015. Tese (Doutorado em Educação Matemática) - Universidade Estadual Paulista Júlio de Mesquita Filho, Rio Claro, 2015.

SANTOS, L. Diferenciação pedagógica: um desafio a enfrentar. Noesis. v. 79, p. 52-57, 2009. Disponivel em: <http://area.fc.ul.pt/en/artigos\%20publicados\%20nacionais/Diferenciacao \%20Pedagogica\%20Noesis.pdf>. Acesso em: maio 2017.

SENA, R. M. Construindo sentidos sobre o ensino de ciências no contexto da pedagogia Waldorf. 2013. Dissertação (Mestrado em Educação Científica e Tecnológica) - Universidade Federal de Santa Catarina, Florianópolis, 2013.

TAVARES, C. S. Uma abordagem sobre o papel do professor na educação Montessori e na tradicional. Pós-Graduação Lato Sensu, Projeto a vez do mestre, Universidade Candido Mendes, Rio de Janeiro, 2006. 
TOMLINSON, C. A.; ALLAN, S. D. Liderar projetos de diferenciação pedagógica. Porto: Asa Editores, 2002.

Recebido: 20 de agosto de 2017

Aceito: 04 de setembro de 2017

Publicado: 19 de setembro de 2017 